\title{
Contribuições do Método História de Vida para ESTUDOS SOBRE IDENTIDADE: O EXEMPLO DO ESTUDO SOBRE PROFESSORAS GERENTES
}

\author{
Contributions of the Life Story Method for Studies on Identity:
} the example of study about female professors in management

positions

\author{
Adílio Renê Almeida Miranda \\ Professor da Universidade Federal de Alfenas (Unifal). Varginha, MG. Brasil. E-mail: adilioadm@yahoo.com.br \\ Mônica Carvalho Alves Cappelle \\ Professora Associada do Departamento de Administração e Economia da Universidade Federal de Lavras. Lavras, MG. Brasil. \\ E-mail:edmo@dae.ufla.br
}

Flávia Luciana Naves Mafra

Professora da Universidade Federal de Lavras (UFLA). Lavras, MG. Brasil. E-mail: flanaves@dae.ufla.br

\section{Resumo}

Recentemente, o método história de vida tem sido usado na área de Administração como uma importante estratégia metodológica nas pesquisas qualitativas. Com esse método busca-se compreender os grupos ou a coletividade a partir de trajetórias de vida individuais. Nesse sentido, o objetivo deste trabalho é discutir a contribuição do método da história de vida para a compreensão da dinâmica identitária de professoras gerentes de uma universidade pública, por meio de um exemplo proveniente de um estudo empírico. Verificou-se, a partir dos relatos de quatro professoras gerentes, que o resgate de memórias do passado $e$ de valores, fatos, normas e acontecimentos ligados à socialização primária e organizacional das entrevistadas contribui para a compreensão da dinâmica identitária delas. Emergiram algumas categorias de análise que expressam relações entre a história de vida e a identidade como: a descontinuidade, a subjetividade e a importância de "dar voz ao sujeito"; o individual e o social e as transformações sócio-históricas: uma interação dinâmica na construção de identidades; e a análise temporal na construção de identidades.

Palavras-chave: História de Vida. Identidade. Métodos de Pesquisa Qualitativa.

\section{Abstract}

Recently, the Life Story Method has been used in the area of Business Administration as an important methodological strategy in qualitative research. The purpose is to understand groups or collective bodies based on individual paths of life. Thus, the goal of this study was to show the contribution of the life story method in understanding the identity dynamics of female professors managing a public university, by means of an example derived from an empirical study. It was observed from the reports of four female professors involved in management that recovery of past memories, as well as of values, facts, standards and occurrences connected with the primary and organizational socialization of the interviewees, contributes to understanding of their identity dynamics. Some categories of analysis emerged that express relationships between life story and identity, e.g., discontinuity, subjectivity and the importance of allowing an individual/subject to speak; the individual and the social sphere and socio-historical transformations, a dynamic interaction in construction of identities; and temporal analysis in construction of identities.

Keywords: Life Story. Identity. Qualitative Research Methods. 


\section{INTRODUÇÃO}

As mudanças que ocorreram na sociedade, além de alterarem profundamente os modos de vida dos indivíduos, possibilitaram também, por meio de inovações tecnológicas, transformações na prática da pesquisa científica. Com isso, na metade do século XX, a utilização da oralidade na pesquisa social passou a constituir um importante avanço no que se refere aos instrumentos para coleta de dados. A partir de então, a realização de entrevistas contou com a utilização de instrumentos tecnológicos como gravadores e filmadoras cada vez mais sofisticados e discretos que, permitiram ao pesquisador apreender e registrar fatos, memórias, histórias e fenômenos, relacionando-os ao indivíduo.

Nessa perspectiva, se insere a proposta do uso da história de vida, como método de pesquisa que busca, por meio da oralidade histórica, ser uma ponte entre o social e o individual. Com ela, busca-se compreender grupos ou a coletividade, a partir de trajetórias de vida individuais. Com isso, é possível compreender as várias particularidades dos objetos/sujeitos de pesquisa ou fenômenos estudados por meio da pesquisa qualitativa, destacando-se, a riqueza de detalhes sobre o processo. (BECKER, 1999)

Na verdade, a história de vida é um tipo de história oral (MEIHY, 1996). Porém, uma de suas especificidades quando comparada à história oral é o vínculo estabelecido entre o pesquisador e o pesquisado. Nesse sentido, para que o narrador conte sua vida, ele precisa sentir confiança e se sentir à vontade.

Na Administração, alguns dos primeiros trabalhos discutindo a contribuição teórico-metodológica da história de vida foram os de Jaime, Godoy e Antonello (2007) e Mageste e Lopes (2007) apresentados no Encontro de Ensino e Pesquisa em Administração e Contabilidade, em sua primeira edição. Tais artigos empreenderam esforços no sentido de evidenciar as potencialidades, as contribuições, os desafios, as críticas e as limitações do uso da história de vida. Mais recentemente, Craide (2011) e Closs e Antonello (2011) também empreenderam tais esforços, no entanto, relacionando-os aos estudos sobre interculturalidade, no caso do primeiro, e à compreensão de processos de aprendizagem gerencial, no segundo trabalho.

Outras pesquisas que adotam história de vida, seja como técnica de coleta de dados ou estratégica metodológica, podem ser destacados como os de Jaime (2001) que objetivou descrever as trajetórias profissionais de dois antropólogos que têm empreendido trabalhos práticos no campo da Administração Mercadológica; Corrêa e Carrieri (2007) que estudaram o assédio moral vivenciado por mulheres em organizações e; Cavedon e Ferraz (2005), que procuraram evidenciar o reflexo das representações sociais na construção de estratégias.

Embora ainda um pouco tímida, verifica-se, portanto, uma crescente utilização da história de vida no campo da Administração. Buscando reforçar tal processo, este artigo pretende discutir a utilização da história de vida como método de pesquisa nos Estudos organizacionais, mais especificamente, nos estudos sobre identidade. O objetivo aqui, portanto, é discutir a contribuição do método da história de vida para a compreensão da dinâmica identitária de professoras gerentes de uma universidade pública, por meio de um exemplo proveniente de um estudo empírico. As professoras gerentes são docentes que ocupam ou ocuparam um cargo gerencial (coordenação de cursos de graduação ou pós-graduação, pró-reitoras, chefes de departamento) na universidade pesquisada.

Apresenta-se, no primeiro momento, uma contextualização histórica destacando as origens da história de vida, conceitos, características, contribuições da utilização do método, ressaltando, logo após, críticas e reflexões quando ao uso e forma de operacionalização. Em seguida, discute-se a re(construção) identitária, considerando-a como um processo que envolve elementos histórico-sociais. Adiante, apresenta-se o exemplo das professoras gerentes, mostrando a contribuição do método história de vida para a compreensão da dinâmica identitária delas. Finalmente, são feitas as considerações finais.

\section{HistóRIA de VIDA: HISTÓRICO E COMPREENSÕES CONCEITUAIS}

A história de vida começou a ser utilizada nas décadas de 1920 e 1930 (BRIOSCHI; TRIGO, 1987; MARRE, 1991; SILVA et al., 2007) por pesquisadores da Escola de Chicago e foi desenvolvida por meio dos trabalhos de Thomas e Znaniecki (1927), na Polônia, e também por antropólogos, segundo o qual, 
buscavam formas de preservação da memória oral de tribos. Outras pesquisas seminais, de acordo com Brioschi e Trigo (1987), foram conduzidas por antropólogos americanos e versavam sobre o testemunho de culturas em extinção e preservação do patrimônio que, pareciam estar desaparecendo em virtude da colonização. No campo da sociologia, Brioschi e Trigo (1987) destacam as pesquisas sobre as categorias consideradas desviantes da sociedade, por exemplo, vagabundos, prostitutas, delinquentes, etc. Entretanto, com a nascente sociologia positivista, a utilização da história de vida começou a cair em desuso.

Outro fator que impediu a utilização da oralidade foi o regime militar que, dentre outras coisas, reprimia a manifestação de opiniões dos indivíduos (FERREIRA, 1996). Sendo assim, as pessoas sentiam medo de expor suas opiniões diante de um contexto de repressão nos meios de comunicação e exposição de determinados tipos de comportamentos quando ligados, principalmente, a questões de ordem política.

Diferentemente da utilização da história de vida no contexto contemporâneo, nos primeiros trabalhos, considerava-se o indivíduo como unidade de pesquisa. Nessa perspectiva, a história de vida era usada apenas para compreender a trajetória do indivíduo e não a trajetória de um grupo (MARRE, 1991). Atualmente, porém, a história de vida é indicada também para a compreensão do social, do coletivo, a partir de histórias individuais.

No estudo das trajetórias, Camargo (1984) relata que o melhor caminho para se compreender a experiência de vida do indivíduo, juntamente com suas ideologias e ações, é por meio da história de vida. Além disso, possibilita ainda a "[...] compreensão de significados implícitos em suas ações" (CAMARGO, 1984, p. 16). Já Brioschi e Trigo (1987), ao refletirem sobre a contribuição da história de vida, chamam a atenção para a compreensão de trajetórias, destacando o sentido histórico e as diversas relações que se estabelecem entre os indivíduos, indicando, dessa forma, a dinâmica das relações sociais. A busca pela compreensão de trajetórias sugere também a construção de um saber sociológico que se ampara pela relação dialética entre a teoria e a prática.

É interessante notar que, entre os diversos autores que escrevem sobre história de vida, ou a utilizam, não há um consenso sobre seu conceito. Becker (1999) reflete sobre a história de vida considerando-a como uma técnica de coleta de dados, ressaltando como uma de suas contribuições para a possibilidade de dar ao pesquisador a noção de processo. Camargo (1984, p. 16), porém, considera a história de vida como método de pesquisa. Segundo a autora, esta abordagem "[...] representa o melhor caminho para se chegar mais perto da experiência vivida do ator - sua ideologia e sua práxis - possibilitanto a compreensão dos significados implícitos em suas ações".

A história de vida, na opinião de Queiroz (1988, p. 208) pode ser definida como:

[...] relato de um narrador sobre sua existência através do tempo, tentando reconstituir os acontecimentos que vivenciou e transmitir a experiência que vivenciou. Narrativa linear e individual dos acontecimentos que nele considera significativos, através dela se delineiam as relações com os membros de seu grupo de sua profissão, de sua camada social, de sua sociedade global, que cabe ao pesquisador desvendar.

Já Becker (1999) compara o uso de história de vida à imagem do mosaico. Segundo o autor:

[...] cada peça acrescentada num mosaico contribui um pouco para nossa compreensão do quadro como um todo. Quando muitas peças já foram colocadas, podemos ver, mais ou menos claramente, os objetos e as pessoas que estão no quadro e sua relação uns com os outros [...] Nenhuma das peças tem uma função maior a cumprir; se não tivermos sua contribuição, há ainda outras maneiras para chegarmos a uma compreensão do todo. (BECKER, 1999, p. 104)

Parece não haver concordância entre os autores quanto à utilização da história de vida como técnica de pesquisa ou como método. De qualquer modo, não se pretende entrar na discussão de categorizá-la como método ou técnica. De fato, acredita-se que o mais importante é utilizá-la de acordo com os objetivos e as necessidades de cada trabalho.

A história de vida é usada, basicamente, para a compreensão de grupos a partir de trajetórias individuais, ou seja, compreender o social a partir do individual, conforme apontam (SILVA et al., 2007; MARRE, 1991; CAMARGO, 1984; QUEIROZ, 1988). Cabe lembrar então, que o indivíduo sempre está inserido dentro de um contexto social e, sendo assim, sua história é 
marcada por fatos, pessoas, organizações e relações, as quais ele estabelece com o "outro". Todavia, Camargo (1984) avança um pouco mais, ao afirmar que, além de buscar a compreensão de um grupo, a história de vida busca, também, apreender a natureza de um período histórico. Dessa forma, pode-se investigar, por exemplo, um determinado período da sociedade, por meio de relatos de experiências de vida individuais.

A vida é uma produção temporal em que se encontram elementos do passado, presente e futuro (DENZIN, 1984). Sendo assim, ela é constituída por vários projetos ao longo dos anos.

[...] a preocupação fundamental do estudo da história de vida e da análise do relacionamento entre a práxis individual e coletiva e a mudança sócio-histórica é compreender de que maneira as vidas, como propriedades biográficas, são possuídas, reunidas, trocadas, ultrapassadas, descartadas, lembradas, memorizadas, dissecadas estudadas, faladas, administradas, controladas, manipuladas, destruídas e desperdiçadas. (DENZIN, 1984, p. 32)

Percebe-se, portanto, que, por meio da recuperação, sistematização e análise de fatos e experiências vividas pelos indivíduos, pode-se compreender momentos históricos, bem como elementos advindos das relações que se dão entre sujeitos. Nesse sentido, a seguir, serão apresentadas mais informações acerca do método de pesquisa história de vida.

\section{Características, Críticas e Forma de Operacionalização}

A história de vida leva em conta a descontinuidade, pois o indivíduo escolhe momentos que para ele são importantes. Nesse caso, o indivíduo não relata os acontecimentos de forma cronológica, mas o faz de acordo com aquilo que ele próprio considera importante (MARRE, 1991). O autor revela que, ao tratar do uso da história de vida, "[...] encaminha-se para uma forma de iniciar a construção de um objeto científico, cujo fundamento é um conjunto real e histórico de relações sociológicas e empíricas vividas por um grupo, mas captadas através de histórias de vida" (MARRE, 1991, p. 10). As experiências vividas constituem-se em totalidades sintéticas, ou seja, somadas formam um todo. Mas, entre elas, não há elo de continuidade, mas muito mais de descontinuidades.

É interessante destacar, também, que, mesmo que a vida dos indivíduos tenha, de alguma maneira, uma continuidade, a forma como ela é contada não segue esse padrão. Isso acontece porque, na história de vida, quem decide o que vai contar é o pesquisado. Sendo assim, a verbalização de suas trajetórias, bem como os fatos e acontecimentos relacionados a ela são lembrados de acordo com a importância que o narrador atribui a eles. Considerando este aspecto, cabe ao pesquisador, no momento de suas análises, estabelecer núcleos de sentido para o temas relatados ao mesmo tempo em que efetua a ligação entre os fatos, contextos e pessoas ao longo da trajetória do indivíduo.

Outra característica da história de vida é a possibilidade de ouvir o que o indivíduo tem a dizer. Marre (1991) comenta sobre o grande desafio da sociologia de tentar compreender a experiência humana. Sendo assim, busca-se "[...] captar como na trajetória histórico-estrutural e social de um determinado grupo, os indivíduos lutam, vivem, sofrem, pensam e se tornam partes constituintes e operantes de uma história humana e da sua estruturação sociológica". (MARRE, 1991, p. 90)

Na visão de Marre (1991), a história de vida possibilita reconstruir uma história não apenas vivida e construída pela elite, mas também pelos humildes ao contribuírem por meio de seus atos, gestos e lutas. Ao contar sua própria história da maneira como achar melhor, o indivíduo pode atribuir importâncias diferentes das do pesquisador no que se refere a determinados fatos. Seria essa então, uma das grandes contribuições da história de vida para a pesquisa qualitativa, comparando-se com as entrevistas semiestruturadas, por exemplo. Nestas últimas, o pesquisador, a priori, já apresenta ao pesquisado os pontos que ele deseja saber ou esclarecer, o que, no entanto, pode não corresponder com aquilo que o entrevistado considera importante. Sendo assim, o uso da história de vida propicia uma maior aproximação à realidade. Isso significa pensar, também, na possibilidade de "dar voz ao sujeito", ou seja, permitir que ele possa contar uma história que muitas vezes não está escrita ou documentada. De outra forma, abrem-se possibilidades para reconstruir uma história de determinados grupos ou categorias sociais, que foi construída apenas pelo 
ponto de vista ou visão de mundo do autor ou escritos de documentos.

Um dos elementos que difere a história de vida da história oral é o vínculo estabelecido entre o pesquisador e o pesquisado (SILVA et al., 2007; DEBERT, 1986; BRIOSCHI; TRIGO, 1987), possibilitando um diálogo entre estas partes (DEBERT, 1986). A proximidade, característica da história de vida, torna-se essencial para que se possa "descortinar" a vida do indivíduo. De acordo com Marre (1991), é muito importante descobrir de que forma o pesquisador pode ajudar o indivíduo a expressar sua vida por meio dos relatos. Sendo assim, o autor relata que a experiência de vida do indivíduo pode ser caracterizada como uma verdadeira "mina de ouro". Para Brioschi e Trigo (1987, p. 633), o pesquisador:

[...] se depara, no seu processo de pesquisa, com um objeto que reage à sua presença, detém um saber que lhe é próprio decorrente de sua experiência de vida, capaz de atribuir significado às suas ações e ao seu discurso, expressando $e$ articulando seus pensamentos à sua maneira.

Nesse sentido, cabe então refletir sobre a questão de o indivíduo, que será pesquisado, ser um mero "objeto de pesquisa". Na reflexão dos autores, parece ficar bem claro que a história de vida permite ao indivíduo reconstruir a si próprio como pessoa que sente, age $e$ reage aos acontecimentos. Portanto, não faz sentido pensar-se em objeto de pesquisa e sim em sujeito de pesquisa, pois este tem o direito de contar sua própria história da forma como achar melhor e, além disso, ainda interagir com o pesquisador, podendo inclusive, criar um discurso que não condiz com a sua prática social.

Outra questão presente nos estudos que utilizam a história de vida é a subjetividade tanto do pesquisador quanto do pesquisado (BRIOSCHI; TRIGO, 1987; QUEIROZ, 1988). Queiroz (1988) faz uma discussão interessante acerca da subjetividade. Na visão da autora, inicialmente, o subjetivo era aquilo que pertencia apenas ao indivíduo e, nesse sentido, distinguia-o das outras pessoas. Todavia, essa compreensão não condiz com a abordagem sociológica, segundo a qual a subjetividade do indivíduo não advém apenas das bases biológicas e psicológicas, mas ela se desenvolve em uma coletividade. Isso significa pensar, por exemplo, que:
[...] as necessidades físicas, inclinações, paixões, prazer e dor, significam reações da parte do indivíduo a algo que captou a partir do exterior, e que só adquirem significado através da mediação do exterior; conforme a sensibilidade dele, serão mais ou menos intensas, desencadearão ou não ações de variado tipo. (QUEIROZ, 1988, p. 218)

Queiroz (1998) ainda tenta esclarecer melhor dizendo que, mesmo que o indivíduo tente compreender-se primeiramente, ele busca traduzir suas "sensações intraduziveis" por meio de instrumentos que lhe deem sentidos variados, amparados por suas vivências com a família, grupo e com a sociedade em geral. Assim, o indivíduo busca instrumentos sociais para compreender o individual. Essa relação estreita da subjetividade com o meio social é que torna a utilização da história de vida ainda mais rica, reforçando, por isso, a maneira de compreender o coletivo a partir do individual.

Brioschi e Trigo (1987), por sua vez, chamam a atenção para a necessidade de o pesquisador compreender que em todo processo de investigação a subjetividade dele estará presente. Portanto, o cuidado maior deverá ser não no sentido de evitar que a subjetividade possa aflorar durante a condução da pesquisa, mas de não deixar que a sua subjetividade se imponha sobre a do narrador/sujeito pesquisado. De outra forma, a subjetividade também está presente nos relatos do narrador. "As histórias de vida podem ser consideradas como produtos subjetivos e simbólicos, possibilitando uma aproximação do sistema de valores e significados do narrador enquanto ser social" (BRIOSCHI; TRIGO, 1987, p. 637). Becker (1999, p. 132) também concorda com os autores mencionados, ao afirmar que "[...] a história de vida pode ser particularmente útil em fornecer-nos palpites sob o lado subjetivo de muitos estudos, no que diz respeito aos processos institucionais sobre os quais suposições não verificadas são muitas vezes elaboradas".

Marre (1991) faz um resumo das características da história de vida: 1) Um dos objetivos da pesquisa participativa, a história de vida, é "devolver a palavra ao pesquisado" (MARRE, 1991, p. 115); 2) há uma relação de igualdade substancial entre o pesquisador e o pesquisado. Isso significa pensar que "[...] ninguém deseja subordinar o outro a seu próprio discurso [...]" (MARRE, 1991, p. 115); 3) a empatia deve ser valorizada no momento das entrevistas em oposição à 
neutralidade, tão comum nas pesquisas realizadas nas ciências naturais; 4) o pesquisador deve ter a capacidade de correr riscos. Isso significa fazer as perguntas certas, avaliações ou críticas pertinentes, a fim de que o pesquisado sinta-se à vontade para verbalizar e rememorar suas histórias.

Na prática, o que se expressa na linguagem das histórias de vida relacionadas com a vivência histórica de determinados grupos sociais, é algo relativo a fatos históricos, estratégias juízos de valores. É, também, algo relativo a relações de poder, dominação, subordinação, cuja desigualdade impregna, penetra ou se irradia na convivência dos homens, comunicando ou se opondo entre si. (MARRE, 1991, p. 119)

Quanto às possibilidades de uso, além de se utilizar a história de vida geralmente nos estudo de caráter qualitativo, Queiroz (1988) chama a atenção para o fato de que mesmo em trabalhos quantitativos, pode-se usar a história de vida no início da pesquisa para que as questões que vão nortear o trabalho sejam levantadas a partir dos relatos do informante e não daquilo que o entrevistador pensa sobre o assunto.

Camargo (1984) alerta também para a possível ocorrência de incoerências entre o discurso dos entrevistados e a sua prática social. Nesse aspecto, a autora afirma que o ator pode mentir ao longo de sua narrativa durante a reconstituição de sua trajetória.

A experiência de Debert (1986) revela que, para se compreender realmente a reconstituição de trajetórias e o sentido que os sujeitos dão a elas, é necessário não ficar apenas na superficialidade da análise dos discursos desses sujeitos, mas "[...] ter acesso ao tipo de práticas que esses discursos engendram" (DEBERT, 1986, p. 146). Nessa perspectiva, o autor chama atenção ainda para a busca do desvendamento da ideologia do discurso, sem apenas "[...] fazer uma leitura ideológica da ideologia de um texto" (DEBERT, 1986, p. 147). Talvez uma possível alternativa à possibilidade do surgimento de incoerências durante os relatos seja as chamadas "contrabiografias" (MARRE, 1991). A contrabiografia é o processo de tentar confrontar o pesquisado sobre os possíveis desvios em relação ao discurso e a realidade. Sendo assim, é muito comum no momento da entrevista o narrador citar pessoas, acontecimentos, ou outros detalhes de sua vida que podem ser comprovados por meio de entrevistas com outros indivíduos ligados à vida do entrevistado. Outra possibilidade talvez seja a utilização conjunta de outras técnicas de pesquisa, como por exemplo, a observação, a pesquisa documental, a de técnica de desenhos, etc.

A história de vida assim como qualquer outro método ou técnica de pesquisa requer uma forma de operacionalização. O método começa a partir do convite do pesquisador e do desejo do entrevistado de contar sua vida. Solicita-se ao sujeito que conte sua história como achar melhor, nos moldes de uma entrevista não estruturada. "É a partir da relação que vai sendo estabelecido, o vínculo, a confiança e a construção de sentidos, que o método se desenvolve. Trata-se da interlocução". (SILVA et al., 2007, p. 32)

Inicialmente, parte-se de uma questão muito ampla do tipo "fale de sua vida" (BRIOSCHI; TRIGO, 1987, p. 636) para um percurso com questões um pouco mais direcionadas a pontos centrais da pesquisa. $\mathrm{Na}$ fase inicial quem define categorias de pensamento $e$ análise, assim como a ordem dos fatos é o narrador do relato. O ideal é que o pesquisador interfira menos possível.

É um método de pesquisa que demanda um período de tempo relativamente longo, pois na opinião de Queiroz (1988, p. 208) "[...] não é em uma ou duas entrevistas que se esgota o informante pode contar de si mesmo". Na prática, para facilitar o entendimento da utilização da história de vida, basta pensar-se em um funil. Então, parte-se de questões bem amplas, que seria, por exemplo, a borda do funil e no decorrer das entrevistas, estas questões vão se afunilando de acordo com os objetivos da pesquisa.

Pode emergir também a necessidade do pesquisador interrogar os informantes sobre os fatos que requerem esclarecimentos, buscando confrontar a história contada com outros tipos de material, como relatórios oficiais e outros fornecidos por pessoas próximas ao informante, com os fatos e com os lugares descritos. (BECKER, 1999)

Quanto ao número de pessoas a serem entrevistadas, Marre (1991) esclarece que na investigação qualitativa, utilizando-se a história de vida, o número de pessoas a serem entrevistadas não é fixo, ou seja, diante de cada entrevista realizada, faz-se uma análise dos fatos e acontecimentos marcantes, bem como conexões como nomes citados. Então, é possível acrescentar novos entrevistados na medida em que se busca investigar novos elementos, configurando-se como um 
dos principais elementos da pesquisa qualitativa, a circularidade (ALENCAR, 2007). As entrevistas como cada sujeito são realizadas até que se atinja o ponto de saturação, ou seja, o ponto em que as informações vão se repetindo.

\section{A Construção Histórico-social da IDENTIDADE}

Na concepção de Ciampa (2001, p. 156-157), "identidade é história", o que permite pensar em múltiplos personagens que compõem esta história, que "[...] ora se conservam, ora se sucedem, ora coexistem, ora se alternam [...]"; o autor explica que "[...] as diferentes maneiras de estruturar as personagens indicam modos de produção da identidade". Ciampa (2001, p. 157) acrescenta, ainda, que a identidade pode ser compreendida como "[...] uma articulação de várias personagens, articulação de igualdades $e$ diferenças, constituindo, e constituída por, uma história pessoal". Os indivíduos podem ser considerados como atores que se transformam à medida que vivem suas personagens (CIAMPA, 2001). O autor esclarece que "[...] as personagens são momentos de identidade, degraus que se sucedem, círculos que se voltam sobre si em movimentos, ao mesmo tempo de progressão $e$ regressão". (CIAMPA, 2001, p. 198)

Essa busca constante por personagens - no caso, por momentos da identidade - só termina quando termina a vida. Por isso, Ciampa (2001) trata a identidade como metamorfose, ou seja, os indivíduos vão se transformando, ao longo da trajetória de vida, de acordo com as experiências vivenciadas pelas personagens em diferentes condições contextuais. Esse movimento é determinado pelas condições históricas, sociais e materiais existentes. Portanto, pode-se dizer que a identidade é uma construção social (NKOMO; COX JÚNIOR, 1997). A partir dessa perspectiva, principalmente, nas organizações, em que mudanças ocorrem constantemente, as identidades dos indivíduos são reconstruídas na medida em que eles experimentam tais mudanças, conforme argumentam Soares e Vieira (2010).

Dubar (2005, p. 136) apresenta um conceito de identidade como o "[...] resultado a um só tempo estável e provisório, individual e coletivo, subjetivo e objetivo, biográfico e estrutural, dos diversos processos de socialização que, conjuntamente, constroem os indivíduos e definem suas instituições". De outra maneira, Dubar (2005, p.135) comenta que, para se apresentar uma definição de identidade, deve-se considerar a noção de dualidade, ou seja, a "[...] identidade para si e a identidade para o outro". Quer dizer que, para se compreender a identidade, cabe, então, analisar a sua dualidade de forma inseparável. A identidade é um processo de construção que depende do próprio julgamento dos indivíduos a respeito de "si" e daquilo que eles acham que os "outros" pensam sobre ele. Dessa forma, Dubar (2005) explica que a identidade é formada pela interação entre a identidade dos indivíduos para "si", que seria aquilo que as pessoas pensam sobre elas mesmas e a identidade para o outro (aquilo que se acha que os outros pensam sobre "si"). Interessante destacar, todavia, que aquilo que as pessoas acham que os "outros" pensam ao seu respeito pode não representar realmente um julgamento correto.

Para compreender a construção de identidades, é necessário entender os modos de constituição dos sujeitos por meio dos processos de socialização. Durante toda a vida, os indivíduos vivenciam e aprendem diversos comportamentos, os quais, de alguma maneira, passam a ser reproduzidos socialmente. É por meio da socialização que as identidades são construídas e reconstruídas. Por isso, torna-se necessário apresentar uma compreensão do que é socialização. Para Dubar (2005, p. XVII, grifos do autor),

[...] a socialização se torna um processo de construção, desconstrução e reconstrução de identidades ligadas às diversas esferas de atividade (principalmente profissional) que cada um encontra durante sua vida e das quais deve aprender a tornar-se ator.

A socialização primária é aquela que ocorre nos primeiros anos da vida do indivíduo, quando ele, estando dentro do espaço familiar, aprende determinados comportamentos, valores, regras, juízos de valor $e$ visões de mundo, compartilhados culturalmente pela família na qual está inserido (BERGER; LUCKMANN, 1985). Em outras palavras, o indivíduo age da forma com ele geralmente vê os outros agindo. $\mathrm{O}$ mundo que ele considera como existente e correto é aquele que os pais ou responsáveis por ele o ensinam. Por 
conseguinte, não há espaços para questionamentos e reflexões acerca de "si", então, o indivíduo "é" aquilo que dizem que ele "é", dentro do contexto familiar.

Mas, ao ter contado com outras estruturas sociais, como escola, igreja, clubes sociais e outros, ele começa a conviver com diversos indivíduos que possuem atributos culturais que, em alguma instância, diferem dos seus, essa é a socialização secundária (BERGER; LUCKMANN, 1985). A partir daí, ocorre um compartilhamento de maneiras de pensar e de se comportar, o que sugere construção e reconstrução de novas identidades para este indivíduo. Com o passar dos anos, ele começa a ter contato com o mundo do trabalho, assim como com instituições de ensino, e passa a atuar mais ativamente na construção social da realidade, quando busca refletir sobre si e sobre a sociedade, de maneira geral. A socialização ocorre de forma permanente $e$ contínua por meio das diversas interações entre fatores biológicos, psíquicos e sociais. É por meio da identificação que se pode tratar a identidade não de maneira essencialista, mas relacional; não como algo acabado, mas como um processo em andamento (HALL, 2006), proporcionando ao indivíduo convivências marcantes decorrentes do grau de identificação vivido em cada momento.

Os processos de construção e reconstrução identitária ocorrem também nas organizações (SCHNURR, 2009; SILVA; VERGARA, 2002), por meio dos processos de socialização organizacional em que se busca a adesão dos indivíduos aos princípios organizacionais. Ao ingressarem em uma organização, indivíduos com características diversas se unem para atuar dentro de um mesmo sistema sociocultural em busca de objetivos pré-determinados. Essa união provoca um compartilhamento de crenças, valores, hábitos, dentre outros, que irão orientar suas ações dentro de um contexto pré-existente, definindo, assim, as suas identidades. (FERNANDES; ZANELLI, 2006)

\section{Exemplo das Professoras GERENTES: A CONTRIBUIÇÃO DA HISTÓRIA \\ DE VIDA PARA A COMPREENSÃO DA DINÂMICA IDENTITÁRIA}

Pretende-se, neste tópico, discutir a contribuição do método da história de vida para os estudos sobre identidade, na perspectiva da construção identitária do indivíduo na organização. Nesse sentido, utilizou-se como exemplo, um estudo feito com professoras gerentes de uma universidade pública com o objetivo de compreender a dinâmica identitária delas. Esse exemplo será usado como uma proposta de mostrar, na prática, como a história de vida contribui para a compreensão da construção da identidade.

Justifica-se tal ligação com base em Watson (2009) que, critica os trabalhos que efetuam a análise da identidade a partir apenas da perspectiva da "identidade na gestão", como se a identidade fosse construída apenas por meio do exercício da função gerencial ou, mesmo, como se existisse uma identidade relacionada, exclusivamente, à vivência gerencial. De fato, as identidades construídas a partir do exercício da função de gerente possuem, de alguma maneira, ligação com outros espaços sociais frequentados pelo indivíduo. Para uma melhor compreensão, o autor sugere que a análise seja feita dentro de um contexto histórico-social. Afinal, a identidade é construída desde a infância $e$, durante toda a vida, sofre modificações acompanhadas, também, de contradições, fragmentações e descontinuidades. Watson (2008) adverte que, ao estudar a dinâmica identitária de gerentes, um grande perigo é não enxergá-los como pessoas inteiras. Nesse sentido, as atividades gerenciais são apenas partes da vida do gerente, sendo as outras partes construções que ocorrem historicamente.

\subsection{O Processo de Coleta e Análise de Dados}

Para a escolha dos sujeitos entrevistados, o primeiro contato foi por telefone, em que o entrevistador solicitava às professoras uma reunião individual para explicar os objetivos e a metodologia da pesquisa. 
O primeiro contato pessoal com as professoras foi nessas reuniões, com duração de cerca de 10 minutos, o que foi importante tanto para o pesquisador quanto para as professoras para que fosse explicado como ocorreria o processo de entrevistas, que envolveria questões pessoais a serem relatadas em vários encontros.

Ao todo, conseguiu-se conversar pessoalmente com seis professoras e todas elas concordaram em participar da pesquisa. Contudo, uma delas não pôde comparecer a duas entrevistas seguidas e não conseguiu agendar novo encontro, razão pela qual deixou de compor o grupo de sujeitos da pesquisa. Assim, foram entrevistadas cinco professoras de distintos departamentos da Universidade.

Ao final dos encontros, o material coletado $e$ previamente analisado foi enviado a cada uma das participantes para que elas verificassem as informações prestadas. Nesse momento, uma das entrevistadas solicitou que seus relatos fossem excluídos da pesquisa. Como parte dos procedimentos do método da história de vida, o pesquisador deve submeter o material sobre os relatos coletados $e$ as análises relacionadas aos mesmos entrevistados, para que possam confirmar, completar ou discordar da interpretação do pesquisador. Então, para a pesquisa, foram considerados os depoimentos de quatro professoras gerentes, às quais foram atribuídos os nomes fictícios de Aparecida, Carolina, Célia e Lílian.

Como o próprio método de pesquisa propõe, as entrevistadas puderam "trazer à memória as coisas do passado", esquecidas com o passar do tempo. As lembranças da infância, da adolescência, da juventude e da vida adulta emergiam como elementos propulsores da "afloração" da subjetividade. Compreender a dinâmica identitária das professoras é, também, tentar expressar esta subjetividade por meio dos relatos orais, gestos e expressões faciais.

Na operacionalização das entrevistas, inicialmente, não se utilizou qualquer forma de estruturação das questões. Mas, logo na primeira entrevista, foi pedido às entrevistadas que contassem sua trajetória ou história de vida. Assim, as entrevistas sempre começavam com a questão: "Conte-me sua história de vida". Então, elas tinham a liberdade de começar por onde desejassem. Mas, quando se percebia que algumas delas contavam muito rapidamente sua história de vida, buscava-se estimulá-las a falar um pouco mais, com o cuidado de não induzir as respostas, sugerindo questões do tipo: "fale sobre sua infância", "fale sobre sua adolescência e juventude", "fale sobre sua vida profissional", "fale sobre momentos marcantes de sua vida", etc.

Após a realização de cada entrevista, era feita uma análise, a fim de que o próximo roteiro fosse elaborado a partir dos relatos da própria entrevistada, até se chegar ao ponto de saturação, que representa o momento em que as informações começam a se repetir e se pode parar a entrevista. Embora houvesse os objetivos específicos de pesquisa norteando-a, pretendia-se que as entrevistadas contassem aquilo que elas considerassem importante. Isso reforça uma característica dos estudos qualitativos, a circularidade da pesquisa, ou seja, coleta de dados/análise, coleta de dados/análise (ALENCAR, 2007). Durante o processo de coleta de dados, verificou-se que o vínculo de proximidade e informalidade estabelecido entre o entrevistador $e$ as entrevistadas permitiu que elas sentissem liberdade e comodidade para relatar suas trajetórias de vida. Durante as entrevistas, duas professoras se emocionaram muito ao recordar de fatos marcantes. Nesse contexto, os relatos das trajetórias de vida representam não apenas uma contribuição para uma pesquisa científica, mas uma oportunidade de reflexão dos momentos marcantes, conquistas, alegrias, tristezas, dificuldades, etc., vivenciados por elas. Dessa forma, ao mesmo tempo em que as entrevistadas contavam suas vidas e refletiam também sobre elas, modificavam-se também como sujeitos sociais. O exercício de "contar a vida" pode ter se tornado mais que uma contribuição para uma pesquisa, mas um prazer ou uma dor.

Isso se refletia em reações curiosas por parte das entrevistadas. Por exemplo, ao ligar para a entrevistada Carolina, a fim de marcar a próxima entrevista, ela responde ao entrevistador dizendo: "É o psicólogo? Que dia é a próxima sessão de terapia?", ou mesmo, "Eu deveria pagar você por estas sessões de terapia porque, quanto termina, a gente sai daqui mais leve". Essas expressões representam a necessidade das professoras de falarem coisas que talvez estivessem esquecidas e que são elementos importantes da dinâmica identitária delas. 


\subsection{Descontinuidades, Subjetividade e a Importância de "dar voz ao sujeito"}

Memórias resgatadas da infância permitiram compreender como as vivências no espaço familiar influenciaram a dinâmica identitária das entrevistas. No caso de uma das professoras, as experiências no mundo do trabalho, principalmente com o exercício da função gerencial, em que ela precisava resolver problemas, enfrentar desafios e tomar decisões importantes, permitiram-lhe superar os "traumas da infância", provenientes da socialização primária.

[...] quando lembro da minha infância, eu era a segunda mais velha, $e$ a minha irmã mais velha, ela tinha um tratamento diferente. A gente achava que ela era a mais, a mais é [...]. Aí. eu fui criada com, tudo que sobrava dela era meu, as roupas, o tratamento mesmo, tudo que ela fazia era mais bonito (pausa, neste momento ela se emociona). [...]. Mas, eu não culpo meus pais, porque ela tinha um carisma, tem até hoje. Assim, talvez eu não tinha isso, né? Acho que isso gerou em mim um pouco de insegurança porque eu achava que a minha irmã era melhor. Acho que este cargo, porque tem gente que entra neste cargo que tem 30 anos, né? Mas eu tinha que entender um pouco esse percurso, de ter valor, de achar que eu conseguia, porque eu achava que eu não conseguiria, entendeu? (Carolina).

Pode-se perceber o quanto a socialização primária, aquela que aconteceu no seio familiar (BERGER; LUCKMANN, 1985), influenciou sua vida, principalmente no contexto profissional. De acordo com os relatos, parece que a entrevistada sempre trouxe o "trauma" de infância de que a irmã mais velha era melhor em todos os aspectos e, além disso, Carolina nutria um sentimento de que sua irmã era preferida pelos pais.

Assumir um cargo gerencial representou uma busca por novas identidades e um desafio a ser vencido. A partir de então, Carolina se identifica com a personagem que ocupa o cargo gerencial e, nesse sentido, por meio da experiência no cargo e das vitórias alcançadas, reconstrói sua identidade. Assim como afirmam Silva e Vergara (2002) e Schnurr (2009), as organizações, assim como a experiência do trabalho, são espaços para a construção de identidades, o que aconteceu com Carolina. É uma busca de reafirmação de si própria como sujeito. Assim, ocorre a re(construção) de suas identidades individuais por meio da identidade profissional.

Ao contar sua história de vida, Carolina remete-se ao contexto da infância, evocando lembranças das vivências em família para, depois, contrapô-las ao seu momento atual, no trabalho. Ela chora durante a entrevista expressando suas emoções e permitindo acessar sua subjetividade. Segundo Brioschi e Trigo (1987) e Queiroz (1988) a subjetividade é uma característica marcante presente no método da história de vida.

As necessidades físicas, inclinações, paixões, prazer e dor, significam reações da parte do indivíduo a algo que captou a partir do exterior, e que só adquirem significado através da mediação do exterior; conforme a sensibilidade dele, serão mais ou menos intensas. (QUEIROZ, 1988, p. 218)

Interessante destacar que, diferentemente das outras entrevistadas, no que diz respeito às trajetórias de vida, Carolina falou muito mais sobre sua infância $e$ adolescência do que sobre sua vida adulta. Esse fato vem ao encontro de uma das contribuições do método da história de vida, segundo o qual quem decide o que é importante e o que vai relatar é o entrevistado, é uma forma de "dar voz ao sujeito" (MARRE, 1991; DEBERT, 1986). O sentido atribuído ao exercício do cargo por ela, expresso no relato, é de superação do trauma de infância.

A descontinuidade da trajetória expressa no relato reforça a ligação entre o trauma de infância e o exercício do cargo. Segundo Marre (1991), ao contar sua história, o indivíduo não relata os acontecimentos de forma cronológica, mas o faz de acordo com o que ele próprio considera importante. Carolina, neste relato, comentou sobre sua infância e, em seguida, sobre o cargo gerencial ocupado, não relatou sobre a formação da família, sobre sua inserção da instituição de ensino. Percebe-se que a descontinuidade é uma maneira de mostrar como o cargo ocupado influencia na transformação da sua vida pessoal. 


\subsection{Individual e o Social e as Transformações Sócio-históricas: uma interação dinâmica na construção de identidades}

A ligação entre os contextos individual e social, segundo Queiroz (1988), expressa relações entre o indivíduo e os grupos do qual faz parte, da sua camada social e da sociedade. Isso porque as pessoas passam por inúmeros processos de socialização ao longo da vida, nos quais são construídos e reconstruídos valores, comportamentos, visões de mundo, etc. Nesse sentido, por meio do relato da professora Lílian, pode-se verificar um exemplo de como a socialização atua na produção de identidades.

Na minha infância e adolescência, a mulher era criada para ser mãe, ficar com o marido incondicionalmente. [...] Porque, claro, meu pai, como todo homem de anos atrás, ele queria ter um filho. E aí, os colegas dele diziam que ele só tinha mulher, então, que o nome dele não iria para a posteridade Então, essas questões, elas influenciaram sim, para pensar em gênero $e$ sexualidade, porque era uma repressão mesmo que sentia na pele né? E, ao saber a possibilidade de estudar essas questões todas, é instigante. [...] Ser criada numa família de mulheres e que a gente foi mostrando que pode ser diferente né, que meu pai ele pode ter orgulho das mulheres né, quer dizer não precisou ter um homem pra fazer isso, então estudar as relações de gênero me subsidiou pra pensar historicamente esse processo todo né, e um processo que eu acho que, se eu assumo um referencial teórico né, eu tenho que tentar ser coerente com esse referencial (Lílian).

Ao analisar a socialização primária da professora Lílian, pode-se entender como ela se identifica ou não com os valores e papéis sociais da época. Como ela mesma conta, viveu em um contexto histórico-familiar em que o nascimento de filhas mulheres não levava o sobrenome do pai para a posteridade porque não garantia a sua continuidade para as próximas gerações. Entre outras características, os homens ainda eram majoritariamente os "provedores da casa", "chefes de família", aqueles que trabalhavam enquanto suas esposas eram as "rainhas do lar" e ficavam em casa, cuidando dos filhos e dos afazeres da casa (PERROT, 1988). Strey (1997) esclarece que, tradicionalmente, a socialização das mulheres foi direcionada para que elas exercessem atividades domésticas. Nessa perspectiva, as mulheres tendiam a se identificar com os papéis de esposa, mãe e dona de casa. Isso dava a elas sentido para a construção da identidade de mulher, ou seja, elas deveriam sentir-se mulheres, sendo mães, esposas e donas de casa. (STREY, 1997)

Esta construção social da identidade de gênero, percebida por meio do relato de Lílian, reflete os valores sociais dominantes da época. Nesse sentido, pode-se verificar mais uma das contribuições do método da história de vida, que é a compreensão de fenômenos, valores e acontecimentos sociais por meio de narrativas individuais (SILVA et al., 2007; MARRE, 1991; CAMARGO, 1984; QUEIROZ, 1988). Isso porque o indivíduo está imerso dentro de um contexto social que pode ser revelado por meio das histórias daqueles que relatam suas trajetórias.

Para as mulheres, até tempos atrás, esperava-se que estivessem imbuídas do cuidado dos filhos, da casa e do marido. Mas, devido às mudanças no campo econômico-político-social, elas têm ocupado, cada vez mais, espaços anteriormente reservados aos homens. Isso, de alguma maneira, incita a articulação de duplas ou até triplas jornadas de trabalho para elas. Não se trata apenas do trabalho no mundo produtivo das organizações, mas muitas delas, talvez a maioria, ainda acumulem as obrigações de dona de casa e mãe. Isso, muitas vezes, isso tem contribuído no surgimento de problemas psicológicos, por exemplo, as crises identitárias. A crise identitária, no caso de Aparecida, surge dessa "obrigação" de ter "superpoderes" e executar múltiplas funções.

A minha psicoterapeuta, que eu consulto eventualmente, ela fala que é isso, é o complexo de cinderela, trata que essa obrigação da onipotência e da onipresença que adoece a pessoa e, no final, a pessoa tira a conclusão que não adianta ter superpoderes (Aparecida).

A "crise" é um termo comum nos tempos atuais. Não apenas os indivíduos, mas as organizações, assim como a própria sociedade ocidental, parecem estar vivendo uma crise (FREITAS, 2000). Isso é reflexo da fragmentação das estruturas sociais que, no passado, serviam de referência para o indivíduo (HALL, 2006). Uma dessas estruturas seriam os papéis sociais de 
gênero que, entre outras coisas, têm se modificado à medida que os valores culturais também se modificam.

A articulação das "obrigações das mulheres" com as obrigações do trabalho cria modelos de supermulheres, onipresentes e que "têm que dar conta de tudo". Mas, parece que, para Aparecida, o esforço para a ascensão na carreira também adquire sentido negativo frente ao cansaço de "ter que dar conta de tudo". Essa perspectiva da "onipresença" das mulheres reflete não apenas algo específico da vida de Aparecida e sim a tendência de articulação de vários papéis na vida da mulher contemporânea. Percebe-se, aqui, outra contribuição da história de vida que, segundo Camargo (1984), permite apreender a natureza de um período histórico. Nesse sentido, surge também a necessidade de compreender e re(construir) as identidades ligadas a estes papéis.

Outro exemplo para compreender as relações que se estabelecem entre o privado e o público pode ser dado por meio do relato de Célia. O depoimento a seguir irá mostrar algumas dessas influências, principalmente no que se refere à identidade vinculada ao lado "maternal" da professora.

Você é muito "mãezona". Você passa a mão na cabeça, a mão na cabeça dos meninos, mas, talvez, seja mesmo pelo fato de a gente ser mãe. É sempre mais assim... receptiva $e$ aconchegante (Célia).

É interessante observar que, em vários momentos das narrativas de história de vida, percebem-se as influências mútuas que se estabelecem entre os espaços do trabalho, familiar e pessoal. A identidade "materna", mesmo sendo uma identidade social, se expressa mais comumente no espaço familiar, mas, pelo relato de Célia, se manifesta no espaço público. Mas, isso não se deve apenas ao fato do exercício da função gerencial, mas também à docência. Esse aspecto seria um fator de diferenciação entre mulheres e homens. Em alguns momentos, ocorre um imbricamento da identidade de professora com a identidade de mãe.

Como destaca Denzin (1984), uma das preocupações da história de vida é compreender as várias mudanças que ocorrem nas trajetórias dos indivíduos por meio do relacionamento existente entre a práxis individual e a coletiva. Dessa forma, analisando o relato de Célia, percebe-se como um comportamento ado- tado na vida privada pode ser levado para o trabalho. A identidade de "mãezona" construída por aqueles que convivem com Célia, segundo a entrevistada, resulta de traços típicos do papel de mãe, tais como estes descritos no relato, ou seja, ser receptiva e aconchegante.

\subsection{A Análise Temporal na Construção de Identidades}

Os depoimentos a seguir são de algumas professoras entrevistadas que também foram alunas de graduação da universidade pesquisada, na época em que havia poucos cursos e estes eram voltados para a área de ciências agrárias e engenharia.

\begin{abstract}
Tanto o ambiente que eu estudei, quanto o ambiente que eu escolhi pra trabalhar, quando eu ingressei na (nome da universidade), nós tínhamos um número muito pequeno de mulheres trabalhando aqui, e na minha turma, de Agronomia, a gente tinha cinco mulheres, e os demais colegas homens (Aparecida).

[...] e realmente a gente ficava meio que deslocada no início, porque eram poucas mesmo [...] Mas tinha que fazer tudo que os meninos faziam. Tinha que arar terra, encher silo, tudo isso a gente fazia, sabe? (Célia).
\end{abstract}

Os depoimentos evidenciam o pequeno número de mulheres no curso de agronomia e, por conta disso, a estratégia identitária desenvolvida pelas alunas era se masculinizarem por meio da negação da diferença. Assim, elas usavam vestimentas típicas de homens, a fim de que a aparência passasse a impressão de uma postura mais firme. Entretanto, essa era uma fase em que há insegurança e mais necessidade por pertencimento aos grupos, aos colegas e de se tornar popular. Ao cobrarem umas das outras este tipo de comportamento, acontecia a socialização pelos pares, em que, muitas vezes, a cobrança não vinha dos homens, mas das próprias alunas.

Mas, ao mesmo tempo em que elas tinham que negar a diferença de gênero perante os colegas, elas também afirmavam a diferença perante a sociedade, pois tinham que se comportar como "moças recatadas", para não serem "mal faladas". Isso mostra um dos conceitos de identidade discutidos por Ciampa (2001) em que a identidade é vista como uma busca entre o igual e o diferente. Para as alunas, perante os colegas 
homens, no aspecto produtivo/intelectual, era preciso ser como eles. No entanto, em relação à sexualidade, o comportamento social da época é que definia como elas deveriam agir. Essa reflexão traz uma importante questão, a de como o mundo produtivo e intelectual ainda está associado aos homens e a sexualidade, às mulheres, mas no sentido negativo. Neste último caso, aos homens, socialmente, é incentivada a exacerbação da virilidade, mas às mulheres cabe a ideia de repressão sexual, de se mostrarem "recatadas". (PERROT, 1988)

Os relatos de Célia e Aparecida, assim como as análises feitas evidenciam novamente a questão da construção de social das identidades de gênero. Outro aspecto pode ser observado que é a produção temporal das histórias de vida (DENZIN, 1984), assim como da dinâmica identitária das entrevistadas. Nessa perspectiva, a análise da dinâmica identitária das pessoas deve ser feita com base em elementos do passado, presente e futuro como destaca Denzin (1984).

O passado é evocado de duas maneiras, como afirmação e como negação. Como afirmador das identidades, professoras gerentes parecem precisar trazer à memória o passado de lutas e dificuldades para dar sentido às conquistas e vitórias. Já no caso de Lílian, como exposto a seguir, ela evoca o passado para negar suas identidades ligadas a ele e, por conseguinte, afirmar suas identidades ligadas ao presente. É uma espécie de negociação entre as identidades do passado $e$ as do presente. (YBEMA et al., 2009)

\begin{abstract}
A Lílian é uma pessoa que vem constituindo a sua identidade de uma forma não fixa, extremamente mutável e com o grande prazer do movimento, porque, assim, quem é a Lilian hoje? Seguramente não é a Lílian que começou aqui na (nome da universidade), não é a Lílian que fez pedagogia, não é a Lílian que fez magistério não é a Lîlian criança (Lîlian).
\end{abstract}

Pelo relato dessa professora, fica claro que suas identidades são construídas em processos reflexivos com a mobilização da consciência (CIAMPA, 2001; MAHEIRIE, 2002). Além disso, a ideia de que as identidades são provisórias, mutáveis e variáveis, é característica do sujeito pós-moderno (HALL, 2006). Lílian se inclui nessa categoria por considerar o "movimento" como elemento que perpassa sua construção identitária.
Ao fazer tal comentário, a professora está querendo reforçar sua posição de sujeito dentro da história, do contexto em que vive. Tanto é que, ao afirmar que a Lílian é uma pessoa que vem constituindo a sua identidade, ela busca passar a ideia de que é um sujeito reflexivo, que não apenas é produto de sociedade, mas que a realidade também é produto de suas construções (BERGER; LUCKMANN, 1985). Ela, diferentemente de outras professoras, busca afirmar sua identidade amparada também pela negação daquilo que ela "não é", e que está relacionado ao seu passado e aos estereótipos de gênero.

A identidade está ligada, ou melhor, ela é revelada, por meio de uma personagem que desempenha papéis dentro da sociedade. O ser humano, como ser social, está dentro de uma teia de relações sociais, ou seja, ele não pode encarnar personagens isolados. Dessa forma, o indivíduo pode ser determinado por aquilo que ele não é, ou seja, pelo que o nega (CIAMPA, 2001). Então, seguramente, na opinião da entrevistada, a Lílian "não é aquilo que ela já foi". Ela rompe com as suas identidades do passado, rompe com a Lílian que começou na universidade, a Lílian que fez pedagogia, rompe com a Lílian criança. Ela não vincula sua identidade à predicação dela, pois, começar na universidade, fazer pedagogia e fazer magistério, não representa, necessariamente, aquilo que ela faz hoje. Pelo contrário, é uma realidade que ela trabalha para transformar.

\section{Considerações Finais}

O objetivo deste trabalho foi o de discutir a contribuição do método da história de vida para a compreensão da dinâmica identitária de professoras gerentes de uma universidade pública, por meio de um exemplo proveniente de um estudo empírico.

A dinâmica identitária das professoras gerentes é uma construção que ocorre ao longo da vida delas ou, segundo Ciampa (2001), é história. Mas, ela passa por vários momentos de reconstrução, pois, é influenciada pelas experiências vivenciadas ao longo da vida, inclusive na infância. Verificou-se, por meio dos relatos, que o resgate de memórias do passado bem como de valores, fatos, normas e acontecimentos ligados à socialização primária e organizacional 
das entrevistadas, contribui para a compreensão da dinâmica identitária delas.

A história de vida configura-se como importante instrumento de pesquisa nos estudos qualitativos, seja pelo fato de possibilitar a compreensão de grupos ou o "coletivo" a partir de trajetórias individuais, ou mesmo por permitir ao pesquisador apreender os elementos que compõe a subjetividade nos indivíduos e nas organizações. No exemplo do estudo das professoras-gerentes, emergiram algumas categorias de análise que expressam relações entre a história de vida e a identidade como: a descontinuidade, subjetividade e a importância de "dar voz ao sujeito"; o individual e o social e as transformações sócio-históricas: uma interação dinâmica na construção de identidades; $e, a$ análise temporal na construção de identidades.

Pelo método da história de vida, ao se permitir ao entrevistado contar sua trajetória, ele relata aquilo que considera importante, ou seja, não é o entrevistador que lhe impõe determinados assuntos ou categorias de questões. Sob esse aspecto, a história de vida permite um retrato mais fiel da realidade. Claro que, mesmo assim, ainda há possibilidade de reprodução de um discurso longe da prática social. Entretanto, técnicas complementares de pesquisa podem ser usadas a fim de confirmar informações e fatos, ou seja, as contrabiografias.

A coerência entre as opções teóricas e metodológicas deste trabalho possibilitou uma convergência analítica que contribuiu para o estudo da identidade. Isso porque a investigação da identidade dos sujeitos da pesquisa foi feita com base na noção da identidade como um processo, evidentemente, inacabado. Há uma forte congruência entre elementos do passado e presente na dinâmica identitária das professoras. Nesde caso, a identidade das professoras, ou melhor, as identidades, foram estudadas com base em suas histórias de vida.

Nesse trabalho, buscou-se apresentar algumas contribuições do uso da história de vida nos estudos sobre identidade, sem a pretensão de abordar todos os seus alcances e limites. Como método de pesquisa, sua utilização ainda é um pouco tímida nos Estudos organizacionais e na Administração, por isso, são amplas as possibilidades de outras pesquisas que utilizem a história de vida, como, por exemplo, trabalhos que abordem a subjetividade dos indivíduos, as relações de poder e as práticas de violência nas organizações; $e$ os vínculos estabelecidos entre os indivíduos e as organizações e as interferências entre ambos.

\section{REFERÊNCIAS}

ALENCAR, E. Pesquisa em turismo. Lavras, MG: Editora UFLA, 2007.

BECKER, H. S. Métodos de pesquisa em Ciências

Sociais. São Paulo: Pioneira, 1999.

BERGER, P.; LUCKMANN, T. A Construção social da

realidade. Petrópolis: Vozes, 1985.

BRIOSCHI, L. R.; TRIGO, M. H. B. Relatos de vida em ciências sociais: considerações metodológicas. Revista Ciência e Cultura, Campinas, SP, v. 39, n. 7, 1987, p. 631-637.

CAMARGO, A. Os Usos da história oral e da história de vida: trabalhando com elites políticas. Revista de Ciências Sociais. Rio de Janeiro, v. 27, n. 1, p. 5-28, 1984.

CAVEDON, N. R.; FERRAZ, D. L. da S. Representações Sociais estratégia em pequenos comércios. Revista de Administração de Empresas, [on-line], v. 4, n. 1, artigo 14, jan.-jul., 2005.

CIAMPA, A. da C. A Estória do Severino e a história da Severina: um ensaio de psicologia social. São Paulo: Brasiliense, 2001.

CLOSS, L. Q.; ANTONELLO, C. S. O Uso da história de vida para compreender processos de aprendizagem gerencial. Revista de Administração da Mackenzie, São Paulo, v. 12, n. 4, jul.-ago., p. 44-74, 2011.

CORRÊA, A. M. H.; CARRIERI, A. P. Percurso semântico do assédio moral na trajetória profissional de mulheres gerentes. Revista de Administração de Empresas, São Paulo, v. 47, n.1, jan.-mar., 2007.

CRAIDE, A. A adoção da História de Vida em pesquisas sobre a interculturalidade: uma nova possibilidade de aplicação no campo da Administração. In: ENCONTRO DE ENSINO E PESQUISA EM ADMINISTRAÇÃO E CONTABILIDADE, III., 2011, João Pessoa. Anais... João Pessoa: EnEPQ, 2011. CD-ROM. 
DEBERT, G. G. Problemas relativos à utilização da história de vida e história oral. In: CARDOSO, R.

A aventura antropológica: teoria e pesquisa. Rio de Janeiro: Paz e Terra, 1986. p. 64-78.

DUBAR, C. A Socialização: construção das identidades sociais e profissionais. São Paulo: Martins Fontes, 2005.

DENZIN, N. K. Interpretando as vidas de pessoas comuns: Sartre, Heidegger e Falkner. Revista de Ciências

Sociais, Rio de Janeiro. v. 27, n. 1, p. 29-43, 1984.

FERREIRA, M. de M. Usos e abusos da história oral. 2. ed. Rio de Janeiro: FGV Editora, 1998.

FERNANDES, K. R.; ZANELLI, J. C. O Processo de construção e reconstrução das identidades dos indivíduos nas organizações. Revista de Administração Contemporânea, Rio de Janeiro, v. 10, n. 1, jan.-mar, p. 48-72, 2006.

FREITAS, M. E. Contexto social e imaginário organizacional moderno. Revista de Administração de Empresas, São Paulo, v. 40, n. 2, abr.-jun, p. 6-15, 2000.

HALL, S. A identidade cultural na pós-

modernidade. 11. ed. Rio de Janeiro: DP\&A, 2006.

JAIME, P. Etnomarketing: antropologia, cultura e consumo. Revista de Administração de Empresas, São Paulo, v. 41, p. 68-77, 2001.

JAIME, P.; GODOY, A. S.; ANTONELLO, C. S. História de vida: origens, debates contemporâneos e possibilidades no campo da administração. In: ENCONTRO DE ENSINO E PESQUISA EM ADMINISTRAÇÃO E CONTABILIDADE, 1., 2007, Recife. Anais... Recife: EnEPQ, 2007. CD-ROM.

QUEIROZ, M. I. P. Relatos orais: do "indizível" ao "dizível". In: SIMSON, Olga de Moraes Von. (Org).

Experimentos com História de vida. Itália-Brasil. São Paulo: Vértice, 1988. p. 14-43.

MAGESTE, G.; LOPES, F. T. O uso da história de vida nos estudos organizacionais. In: ENCONTRO DE ENSINO E PESQUISA EM ADMINISTRAÇÃO E CONTABILIDADE, 1., 2007, Recife. Anais... Recife: EnEPQ, 2007. CD-ROM.
MAHEIRIE, K. Constituição do sujeito, subjetividade e identidade. Interações: estudos e pesquisas em psicologia, São Paulo, v. 13, n. 7, jan.-jun, p. 31-44, 2002.

MARRE, J. L. História de Vida e Método Biográfico. Cadernos de Sociologia, Porto Alegre, v. 3, n. 3, jan.jul., p. 89-141, 1991.

MEIHY, J. C. S. B. Manual de história oral. São Paulo: Edições Loyola, 1996.

NKOMO, S. M.; COX JÚNIOR, T. Diversidade e identidade nas organizações. In: CLEGG, S. R.; HARDY, C.; NORD, W. R. (Org.). Handbook de estudos organizacionais: modelos de análise e novas questões em estudos organizacionais. São Paulo: Atlas, 1997. p. 332-358.

PERROT, M. Os excluídos da história: operários, mulheres e prisioneiros. Rio de Janeiro: Paz e Terra, 1988.

SCHNURR, S. Constructing leader identities through teasing at work. Journal of Pragmatics, Amsterdan, v. 41, n. 6, June, p. 1.125-1.138, 2009.

SILVA, J. R. G. da; VERGARA, S. C. Mudança organizacional $e$ as múltiplas relações que afetam a reconstrução das identidades dos indivíduos. In: ENCONTRO NACIONAL DE PÓS-GRADUAÇÃO EM ADMINISTRAÇÃO, 33., 2002, São Paulo. Anais... São Paulo: EnANPAD, 2002. CD-ROM.

SILVA. A. P. et al. Conte-me sua história: reflexões sobre o método de História de Vida. Mosaico: estudos em psicologia. Belo Horizonte, v. 1, n.1, p.25-35, 2007.

SOARES, D. C.; VIEIRA, A. Reestruturação

Organizacional e Reconstrução da Identidade: um Estudo de Caso em uma empresa de telecomunicações. Revista de Ciências da Administração, Florianópolis, v. 12, n. 26, p. 92-115, jan.-abril, 2010.

STREY, M. N. A mulher, seu trabalho, sua família e seus conflitos. In: STREY, M. N. (Org.). Mulher, estudos de gênero. São Leopoldo: UNISINOS, 1997. p. 60-75.

THOMAS, W. I.; ZNANIECKI, F. The Polish Peasant in Europe and America. 2. ed. New York : Dover, 1927. 
Adílio Renê Almeida Miranda • Mônica Carvalho Alves Cappelle • Flávia Luciana Naves Mafra

WATSON, T. J. Managing identity: identity work, personal predicaments and structural circumstances. Organization Science, Providence, v. 15, n. 1, Jan.-Mar, p. 121-43, 2008.

WATSON, T. J. Narrative, life story and manager identity: a case study in autobiographical identity work. Human

Relations, Thousand Oaks, v. 62, n. 3, Mar, p. 425-452, 2009.

YBEMA, S. et al. Articulating identities. Human

Relations, Thousand Oaks, v. 62, n. 3, Mar, p. 299-322, 2009. 